\section{$\underset{\substack{\text { hommes } \\ \text { \& migrations }}}{ }$}

\section{Hommes \& migrations}

Revue française de référence sur les dynamiques

migratoires

1294 | 2011

L'intégration en débat

\title{
Abdelkader Railane, En pleine face
}

Plombières-les-Bains, Ex æquo, 2011, 167 pages, 16 euros

\section{Mustapha Harzoune}

\section{(2) OpenEdition}

1 Journals

\section{Édition électronique}

URL : http://journals.openedition.org/hommesmigrations/603

DOI : 10.4000/hommesmigrations.603

ISSN : 2262-3353

\section{Éditeur}

Musée national de l'histoire de l'immigration

\section{Édition imprimée}

Date de publication : 1 novembre 2011

Pagination : 143-144

ISSN : 1142-852X

\section{Référence électronique}

Mustapha Harzoune, « Abdelkader Railane, En pleine face», Hommes \& migrations [En ligne], 1294

2011, mis en ligne le 29 mai 2013, consulté le 22 septembre 2020. URL : http://

journals.openedition.org/hommesmigrations/603 ; DOI : https://doi.org/10.4000/hommesmigrations. 603

Ce document a été généré automatiquement le 22 septembre 2020.

Tous droits réservés 


\title{
Abdelkader Railane, En pleine face
}

\author{
Plombières-les-Bains, Ex æquo, 2011, 167 pages, 16 euros
}

\author{
Mustapha Harzoune
}

\section{RÉFÉRENCE}

Abdelkader Railane, En pleine face, Plombières-les-Bains, Ex æquo, 2011, 167 pages, 16 euros

1 En pleine face ou comment un agneau promis au sacrifice abrahamique en renversant notre héros encore en couche-culotte transforma sa vie. Car le choc fut rude. Le nez du "tchiot" (nous sommes du côté de Douai) ne résista pas à la charge. Affublé à tout jamais d'un massif organe, marri et un temps frustré, Abdelréda décida, à l'âge où les boutons d'acmé pointent, que l'habit ferait bien le moine. Puisqu'un tendre agneau lui avait donné une gueule de dur à cuir, un tarin de boxeur, eh bien soit, Abdelréda tâtera de l'art pugilistique et basta des moqueries. Bien lui en prit.

2 C'est son histoire qu'il raconte ici, celle d'un môme de cité. Les négligences et les mauvaises transcriptions des mots de la langue arabe de la maison d'édition comme les maladresses de l'écriture ne doivent pas masquer l'intérêt de ce texte qui relève plus du témoignage que du roman. Abdelkader Railane écrit en toute franchise, il ne cache rien de ce que ces cités peuvent charrier de violences, barbaries, racisme, sexisme, frustrations sexuelles ${ }^{1}$, homophobie, tartufferies islamistes, bêtises tous azimuts qui accablent les bons élèves, les tendres et autres romantiques... "Ce n'est pas simple de vivre dans une cité. Je dois dissimuler une partie de ma personnalité et ne montrer que celle qui convient à mon environnement. Tel un caméléon, je dois jongler avec mes différentes personnalités (...)." Abdelkader Railane écrit avec tendresse aussi et montre comment ce gamin des cités qui a biberonné à la haine de l'autre et notamment des "Gaulois" et autres "pur porc" fait, par les tripes et par le cœur, l'expérience d'une autre "lecture, différente de celle de la cité", de "ces mécréants de Français" jusqu'à y compris Monsieur Henno trop vite étiqueté "raciste". C'est une certaine doxa que fait tomber ici l'auteur, 
celle qui se nourrit d'un brin de parano, d'une dose de victimisation et d'une bonne rasade de rejet de l'autre.

Enfin, Abdelkader Railane écrit avec sensibilité, notamment les pages consacrées à la figure paternelle. Celui que l'on surnomme le "Hadj" (alors qu'il n'a jamais fait le pèlerinage) est le père d'une belle couvée, pas moins de dix enfants. L'homme est droit, honnête, généreux. Courageux, indifférent à la pression sociale, il soutient l'émancipation de ses enfants, de ses filles en premier lieu. Il appartient à cette génération pour qui Madame la France n'est qu'une amante de passage. Un passage pour mieux revenir "au pays", riche de quelques économies et d'une maison sortie de la terre des ancêtres qui en a englouti aussi pas mal de ses économies d'ouvrier.

Abdelréda a 14 ans et ses qualités de boxeur le font remarquer. Bon styliste, il a aussi du punch, ses coups font mal. De plus, il se découvre une rage intérieure. Pour être inquiétante, elle lui assure quelques succès. C'est le moment choisi par son père pour annoncer à la famille réunie autour du dominical couscous que le temps est enfin venu de plier bagages et de "rentrer" en Algérie. L'homme est venu en France pour trimer, il a trimé. Il est venu en France pour "faire" un peu d'argent, il a mis de côté un maigre pécule. Il est parti avec le rêve de revenir. Son rêve, il croit, au soir de sa vie, pouvoir le toucher du doigt. Mais voilà, ses gamins nourrissent d'autres rêves. Et pas seulement Abdelréda qui se rend compte que cette France, à qui il n'a eu de cesse de retourner son mépris, il y tient. "À peine ai-je eu le temps de m'intégrer qu'on me désintègre." Ses frères et sœurs, aînés, mariés et installés ne sont pas concernés par le projet paternel. Pourtant, pour eux aussi, voir les parents s'en retourner avec les plus jeunes serait un crèvecœur. Alors un contrat est passé : si Abdelréda obtient le titre de champion de la région Nord, tous resteront "dans ce pays que j'aime". "C'est bizarre, on est constamment en train de critiquer ce pays, mais on refuse de le quitter." Abdelkader Railane souligne les difficultés de bien des gamins emberlificotés dans les filets d'une double filiation, d'une double fidélité, tracassés par un dialogue intérieur incessant, parfois jusqu'au trouble, jusqu'au malaise. Ces gamins doivent inventer un autre rapport aux autres et au monde. La gestation est difficile, exigeante mais indispensable: "Les transitions entre le temps passé avec ma communauté ethnique et religieuse et celui partagé avec ma communauté sociale et sportive sont très difficiles. (...) Je dois faire preuve d'une profonde tolérance pour ne pas rejeter l'un ou l'autre de mes amis. Mais le vrai moi, où se situe-t-il ? (en fait, je ne sais pas, je suis dans la merde quoi!)", dit le gamin de 14 ans. Cette histoire rappelle à quel point il est urgent d'aider les plus jeunes à lever cette contradiction intime.

5 Abdelréda, lui, a choisi. Il va boxer pour pouvoir rester en France, soutenu par une cité entière, les profs et les élèves du collège, une ville et même une région. Soutenu aussi par... son père.

"Mes parents ont réussi à s'installer dans un pays qu'ils ne connaissaient pas, avec des codes qu'ils ne maîtrisaient pas et une langue qui leur était inconnue. Non seulement ils s'y sont intégrés, mais ils ont élevé une famille de dix enfants, tous ont une activité, soit étudiante, soit salariée. Je considère que l'hospitalité qui leur a été faite est justement payée de retour. Notre famille ne coûte pas à la France, elle rapporte. Le racisme que je subis est d'autant plus difficile à vivre quand on ne se sent redevable de rien."

Le roman d'Abdelkader Railane défile en 12 rounds. Le destin d'Abdelréda se joue, lui, en trois reprises. 


\section{NOTES}

1. Voir aussi le récent roman de Kaoutar Harchi, L'Ampleur du saccage, Paris, Actes Sud, 2011. 